\title{
Differential phagocytic ability of the circulating haemocyte types of the carpet shell clam Ruditapes decussatus (Mollusca: Bivalvia)
}

\author{
Carmen López ${ }^{1}$, María J. Carballal ${ }^{1}$, Carlos Azevedo ${ }^{2}$, Antonio Villalba ${ }^{1}$ \\ ${ }^{1}$ Centre of Marine Research, Ministry of Fisheries and Aquaculture of Galicia, POB 208, E-36600 Vilagarcía de Arousa, \\ Pontevedra, Spain \\ ${ }^{2}$ Department of Cell Biology, Institute of Biomedical Sciences, University of Porto, P-4000 Porto, Portugal
}

\begin{abstract}
Phagocytosis of foreign materials by haemocytes is an important aspect of the internal defence of bivalve molluscs. Two main haemocyte types can be distinguished in the haemolymph of the clam Ruditapes decussatus: granulocytes and hyalinocytes. The ability of clam haemocytes to phagocytose zymosan particles, Vibrio P1 cells and trophozoites of the protistan parasite Perkinsus atlanticus was demonstrated by means of in vitro assays. However, clam haemocytes did not phagocytose $P$. atlanticus zoospores in the assays. Granulocytes showed the highest phagocytic capacity in each assay. Phagocytic capacity of haemocytes was not significantly affected by clam age. An ultrastructural study of phagocytosis showed the following sequence of events: engulfment of particles by pseudopods, formation of a phagocytic vacuole, fusion of lysosomes with the phagocytic vacuole, and digestion of the particles giving rise to residual bodies that might be discharged.
\end{abstract}

KEY WORDS: Ruditapes decussatus - Haemocytes - Phagocytosis - Vibrio P1 Perkinsus atlanticus

\section{INTRODUCTION}

It is well-known that haemocytes are involved in the immune system of bivalve molluscs. Bivalve haemocytes are usually classified into 2 types, granulocytes and hyalinocytes (Cheng 1975, Auffret 1988). Nevertheless, heterogeneous cell populations are not precisely characterized in terms of their respective defence functions.

Phagocytosis of non-self materials by haemocytes is one of the defence mechanisms of bivalve molluscs (Feng 1988). It is known that haemocytes are the phagocytic cells in bivalve molluscs.

Infectious diseases are a very important problem in mollusc aquaculture. Among bivalve molluscs commercial losses occur as a result of mortalities caused by the presence of protozoa, rickettsia and chlamydia, and bacteria and viruses (Lauckner 1983). The availability of pathogen purification protocols (Mialhe et al. 1985, 1988, Le Gall \& Mialhe 1992) has permitted the study of different aspects of defence mechanisms against a number of pathogens.

Several authors have studied the phagocytosis process and associated cytotoxic mechanisms in species belonging to the Veneridae family: e.g. Mercenaria mercenaria (Anderson 1994) and Ruditapes decussatus (López et al. 1994). R. decussatus is one of the most important species of this family in Europe, from a commercial point of view. Populations of this species are affected by 2 important epizootics caused by Perkinsus atlanticus (Azevedo 1989) and Vibrio P1 (Paillard et al. 1994).

Morphological characterization of the circulating haemocytes of Ruditapes decussatus was studied as a first step of research on cellular defence and 2 cell types were found, granulocytes and hyalinocytes (López et al. 1997).

The purpose of the present study was to evaluate the phagocytic capacity of the haemocyte types of Ruditapes decussatus through in vitro assays using live 
cells of the clam pathogens mentioned above and inert particles as phagocytosis stimulants

\section{MATERIALS AND METHODS}

Haemolymph collection. Haemolymph was taken from the posterior adductor muscle of clams Ruditapes decussatus using a syringe, through a hole made in the shell margin. It was collected diluted 1:3 in a modified anti-aggregant Alsever solution (MAS) (20.80 g $\mathrm{l}^{-1}$ glucose, $8.00 \mathrm{~g} \mathrm{l}^{-1}$ sodium citrate, $3.36 \mathrm{~g} \mathrm{l}^{-1}$ EDTA, $22.50 \mathrm{~g} \mathrm{l}^{-1}$ sodium chloride in distilled water). Haemolymph of 5 specimens was pooled and the number of haemocytes was estimated with a Malassez haemocytometer.

For phagocytosis assays, the concentration in MAS was reduced to $3 \%$ by centrifugation, supernatant removal, and resuspension of haemocytes in sterile filtered seawater (SFSW).

Phagocytosis assays. Light microscopy. In phagocytosis assays zymosan, Vibrio P1 bacteria (VP1), trophozoites and zoospores of Perkinsus atlanticus were used as phagocytosis stimulants.

In the in vitro phagocytosis assays, $2 \times 10^{5}$ haemocytes were incubated in suspension with different particle stimulants for $1 \mathrm{~h}$ at room temperature (Fries \& Tripp 1980), in Eppendorf tubes. The particle-to-haemocyte ratio was 5:1 for zymosan, trophozoites and zoospores of Perkinsus atlanticus and 20:1 for VP1. After the incubation, cytospin slides were performed, fixed, stained with rapid Hemacolor kit (Merck) and mounted.

The percentage of haemocytes corresponding to each cell type in the cytospins was estimated after examination of 300 cells by light microscopy.

A similar in vitro assay, with zymosan as phagocytosis stimulant, was performed from 2 groups of 15 clams of different ages $(31.00 \pm 0.31 \mathrm{~mm}$ and $23.93 \pm 0.27 \mathrm{~mm}$ in longest axis) to test the influence of age on phagocytic capacity.

Phagocytosis assays. Electron microscopy. Similar in vitro assays were performed to study ultrastructural aspects of the process of phagocytosis. The number of haemocytes in these assays was $3 \times 10^{6}$ and zymosan and VP1 were used as phagocytosis stimulant. No stage of Perkinsus atlanticus was used in these assays. After incubation, the suspension was fixed with $2.5 \%$ glutaraldehyde in PIPES buffer $(0.1 \mathrm{M}$, at pH 7.2 and $7 \%$ sucrose) for $1 \mathrm{~h}$ at $4^{\circ} \mathrm{C}$, and centrifuged $(750 \times \mathrm{g}$. 10 min). The pellet was washed in PIPES buffer with sucrose for $2 \mathrm{~h}$ at $4^{\circ} \mathrm{C}$, and post-fixed in $1 \%$ osmium tetroxide in the buffer for $75 \mathrm{~min}$ at $4^{\circ} \mathrm{C}$. The cells were then embedded in $1.5 \%$ agar at $40^{\circ} \mathrm{C}$, and quickly centrifuged $(1700 \times g, 5 \mathrm{~min})$. The pellet was dehydrated and embedded in Epon resin. Ultrathin sections (50 to
$70 \mathrm{~nm}$ ) were stained with uranyl acetate and lead citrate and examined in a transmission electron microscope (Jeol100CXII).

Production of Perkinsus atlanticus zoospores. Gills of clams which were heavily infected with $P$. atlanticus were incubated in fluid thioglycollate medium (FTM) at room temperature, in the dark, for $3 \mathrm{~d}$ (Ray 1966). Gills were then removed from FTM, blotted on filter paper, transferred to a Petri dish with SFSW containing antibiotics (Penicillin G 500 units $\mathrm{ml}^{-1}$ and streptomycin $500 \mathrm{mg} \mathrm{ml}^{-1}$ ) and chopped with a scalpel. After attachment of the zoosporangia to the base of Petri dish, the supernatant was poured into another dish (carefully, to prevent the detachment of zoosporangia). Then, the first Petri dish was filled with SFSW with antibiotics and this was repeated in the other Petri dishes. Petri dishes were kept at $28^{\circ} \mathrm{C}$ and it was possible to see zoospores in the SFSW on the third day. Zoospores were observed to be actively motile just before the performance of in vitro phagocytosis assays.

purification of trophozoites of Perkinsus atlanticus. The following procedure was adapted from the procedure for the purification of Bonamia ostreae from Ostrea edulis (Mialhe et al. 1988).

Only gills from Ruditapes decussatus heavily infected with Perkinsus atlanticus were used in the purification. Clams that were heavily infected could be distinguished by naked eye because white pustules were visible in the gills and mantle. Up to 12 clams were used in each purification.

Gills were homogenised with FSW with the addition of $0.5 \%$ Tween 80 (FSWT). The homogenate was then sieved progressively through 100,75 and $20 \mu$ mylon meshes. The resultant filtrate was spun at $2500 \times g$ for $30 \mathrm{~min}$ at $8^{\circ} \mathrm{C}$. The pellet was suspended in FSWT and layered onto a cushion of $15 \%$ sucrose in FSWT. After centrifugation, the supernatant was discarded and the pellet diluted in FSWT and layered onto a gradient of sucrose in FSWT (35\% and 15\%), and centrifuged again. Trophozoites were found at the interface $15 \% / 35 \%$. This fraction was resuspended in FSWT and spun, and the pellet was resuspended in $1 \mathrm{ml}$ of FSWT and layered onto a Percoll gradient (10, $20,30,40$ and $50 \%$ ), containing $0.5 \mathrm{M} \mathrm{NaCl}$ to prevent osmotic shock in trophozoites. This gradient was spun and trophozoites were found at the interfaces between $20 \% / 30 \%$ and $30 \% / 40 \%$. These fractions were collected with a syringe. An equivalent volume of FSW was added and the solution layered onto a cushion of $15 \%$ sucrose in FSW (to remove the Percoll) and centrifuged. The supernatant was discarded and the trophozoites which were found in the pellets were resuspended in FSW and centrifuged as a final rinse.

Vibrio P1 culture. The strain Vibrio P1 used in this study were provided by the IFREMER laboratory (La 
Tremblade, France). The bacteria were maintained in marine agar (Difco) at $4^{\circ} \mathrm{C}$. For phagocytosis assays VP1 was seeded in marine broth (Difco). The number of VP1 was determined by measuring the optical density $\left(1.25 \mathrm{OD}\right.$ is equivalent to $\left.1500 \times 10^{6} \mathrm{VP} 1 \mathrm{ml}^{-1}\right)$. The marine broth was eliminated by centrifugation $(2000 \times$ $g, 15 \mathrm{~min}$ ); VP1 was resuspended in FSW and measured again

Zymosan. Preparation of a suspension of yeast cell walls using zymosan A (Sigma, USA) followed that described by Dikkeboom et al. (1987).

\section{RESULTS}

\section{Phagocytosis of zymosan assays}

Both granulocytes and hyalinocytes showed phagocytic capacity in the in vitro phagocytosis assays with zymosan, although this capacity was higher in granulocytes. Of total haemocytes, $49 \%$ phagocytosed zymosan particles (Fig. 1). Of this population, $72.4 \%$ of the acidophilic granulocytes and $40.9 \%$ of the basophilic granulocytes had internalized zymosan particles at the end of the assays, whereas only $3.4 \%$ of the hyalinocytes had internalized particles. In most of the cells that had phagocytosed, 1 or 2 zymosan particles were observed regardless of cell type. Higher numbers of phagocytosed particles (up to 8) were occasionally observed.

The ultrastructural study allowed observation of entire zymosan particles inside primary phagosomes and partially digested particles in secondary phagosomes (Fig. 2). The number of cytoplasmic granules was lower in granulocytes with internalized zymosan, compared to those granulocytes without phagocytosed zymosan. This difference was probably due to the fusion of granules with primary phagosomes after zymosan internalization. In advanced stages of the phagocytosis process, haemocytes showed a vacuolated appearance with glycogen particles in the cytoplasm and highly degraded material in secondary phagosomes. Images of residual material discharge from haemocytes could be observed.

\section{Phagocytosis of VP1 assays}

In this case, $55.3 \%$ of the haemocytes had phagocytosed bacteria Vibrio P1 at the end of the assay. As in the previous case, each haemocyte type was able to phagocytose bacteria. Acidophilic granulocytes appeared as the most phagocytic $176.6 \%$ of them internalized bacteria) followed by basophilic granulocytes (39.7\%) and hyalinocytes (33.0\%). Up to
10 phagocytosed bacteria were observed in a single cell (Fig. 3).

Electron microscopy confirmed the capacity of haemocytes to phagocytose VP1 bacteria. Partially degraded VP1 bacteria were observed inside secondary phagosomes (Fig. 4), and rarely inside primary phagosomes. Haemocytes with phagocytosed bacteria showed some vacuoles with residual materials. The presence of small vesicles detached from the cytoplasmic membrane was very common in phagocytic haemocytes.

\section{Phagocytosis of trophozoites and zoospores of Perkinsus atlanticus}

It was not possible to distinguish the haemocyte type after trophozoites had been internalized because of the large size of the latter. However, it was possible to distinguish the haemocyte type in the trophozoite engulfment stage. Internalized trophozoites were found in $43.7 \%$ of the haemocytes at the end of the assays. At the engulfment stage, $41.1 \%$ of the acidophilic granulocytes, $37.2 \%$ of the basophilic granulocytes and $19.0 \%$ of the hyalinocytes were found to be engaged in the process.

In contrast, clam haemocytes were not able to phagocytose zoospores of Perkinsus atlanticus in the in vitro assays.

\section{Influence of clam age in phagocytic capacity}

Table 1 shows the percentages of haemocytes with phagocytosed Zymosan in 2 groups of different age clams. The difference found between the groups was not significant.

\section{DISCUSSION}

The results of in vitro assays showed that all clam haemocyte types had phagocytic capacity, although granulocytes showed a greater ability. These findings are consistent with results reported from Crassostrea

Table 1. Percentage of haemocyte types of Ruditapes decussatus with phagocytosed zymosan particles corresponding to 2 groups of clams of different ages. Mean size \pm standard error corresponding to each clam group are indicated in parentheses

\begin{tabular}{|lcc|}
\hline Haemocyte type & $\begin{array}{c}\text { Older clams } \\
(31.00 \pm 0.31 \mathrm{~mm})\end{array}$ & $\begin{array}{c}\text { Younger clams } \\
(23.93 \pm 0.27 \mathrm{~mm})\end{array}$ \\
\hline Hyalinocytes & $4.71 \%$ & $8.81 \%$ \\
Basophilic granulocytes & $38.89 \%$ & $41.18 \%$ \\
Acidophilic granulocytes & $74.68 \%$ & $73.08 \%$ \\
Total & $47.78 \%$ & $51.33 \%$ \\
\hline
\end{tabular}




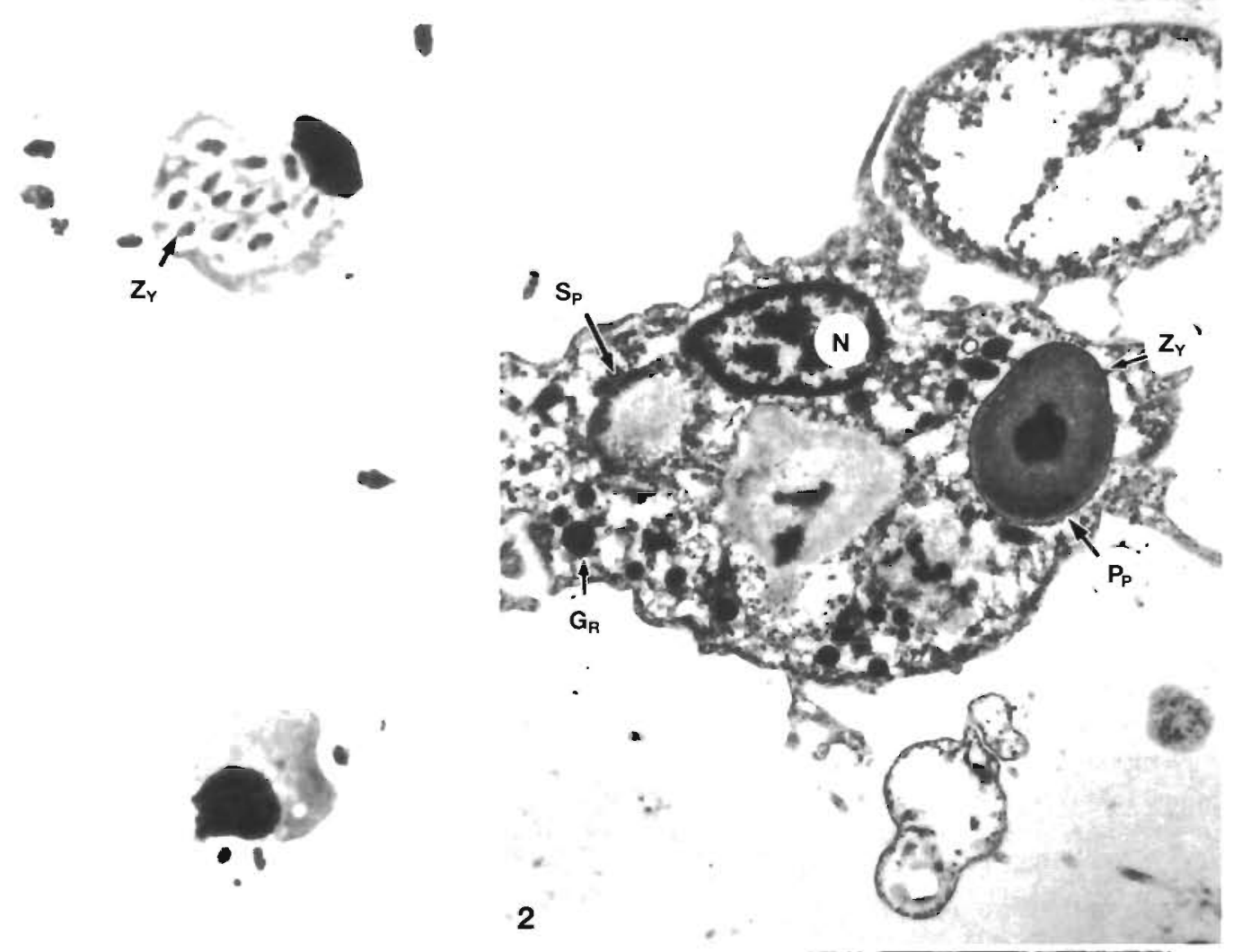

\section{1}

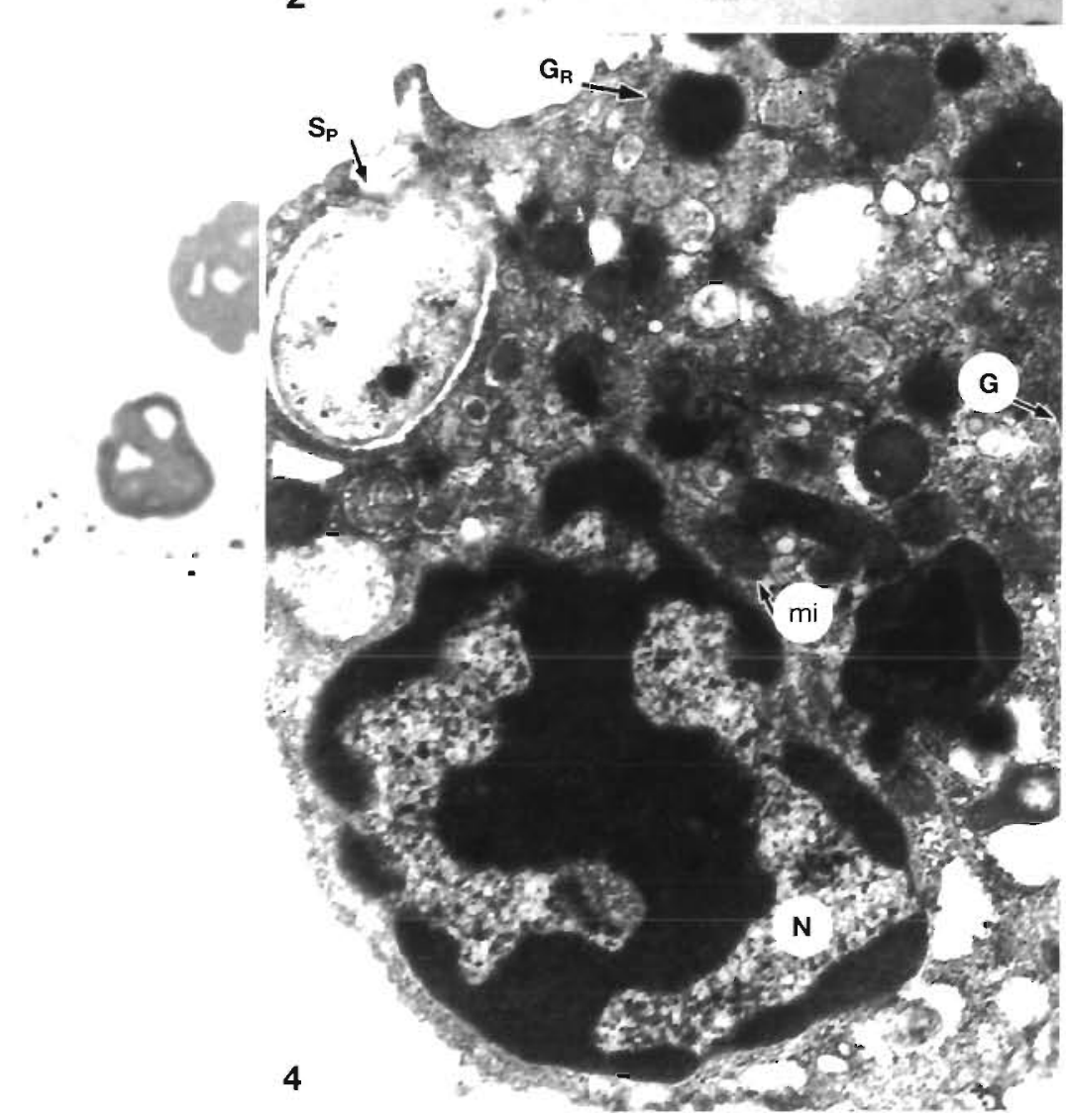


Figs. 1 to 4. Ruditapes decussatus haemocytes. Fig. 1. Brightfield micrograph haemocytes after exposure to zymosan (Zy) particles. $(\times 1400)$. Fig. 2. Utrastructure of a granulocyte with phagocytosed zymosan particles. N: nucleus; $Z_{Y}: z_{y m o s a n} P_{p}:$ primary phagosome; $S_{p}$ : secondary phagosome; $G_{R}$ : granule. $(\times 5800)$. Fig. 3. Brightfield micrograph of haemocytes after exposure to Vibrio P1 (VP1). $(\times 1400)$. Fig. 4. Ultrastructure of a granulocyte with phagocytosed Vibrio P1 (VP1) bacterium within secondary phagosome $\left(S_{p}\right)$. N: nucleus; $G_{R}$ : granule; G: golgi complex; mi: mitochondria. $(\times 15200)$

virginica and Mercenaria mercenaria by Foley \& Cheng (1975) and Renwrantz et al. (1979) from C. virginica. In contrast, Ruddell (1971) indicated that in C. virginica the agranular amebocytes appeared to have greater phagocytic ability. However, Hawkins \& Howse (1982) for C. virginica and Auffret (1986) for Ostrea edulis found that only the granulocyte type was phagocytic. Among granulocytes, the acidophilic granulocytes of Ruditapes decussatus were found to be more phagocytic, which is in agreement with the observations of Pipe et al. (1994). The higher phagocytic capacity observed in $R$. decussatus granulocytes is consistent with the accurrence of higher levels of hydrolytic enzymes in these cells (López et al. in press). The function of bivalve hyalinocytes is not known but it is possible that they have another specific function different to phagocytosis. Hose et al. (1990) and Clare \& Lumb (1994) indicated that crustacean hyalinocytes have a role in the clotting process. Bivalves do not have humoral clotting factors but Suzuki et al. (1991) indicated that agranular haemocytes of pearl oyster Pinctada fucata show the ability to form a cellular sheath and produce an extracellular matrix in the wound healing process

Around $50 \%$ of Ruditapes decussatus haemocytes showed phagocytic ability in our assays. Fries \& Tripp (1980) noticed phagocytic ability in $100 \%$ of Mercenaria mercenaria haemocytes. Differences could be due to experimental procedures or to intrinsic properties of the bivalve species. La Peyre et al. (1995) reported a significant difference in the percentage of phagocytic haemocytes between Crassostrea gigas and $C$. virginica using the same experimental procedure with both species.

Ruditapes decussatus haemocytes showed the ability to phagocytose all stimulant particles used in the assays, except zoospores of Perkinsus atlanticus. In contrast, haemocytes of Crassostrea virginica are able to phagocytose zoospores of $P$. marinus. Different experimental conditions should be used to further study the inability of clam haemocytes to phagocytose $P$. atlanticus zoospores. Feng $(1966,1967)$ and Feng \& Stauber (1968) found that Haplosporidiun nelsoni, Hexamita nelsoni and Staphylococus aureus induced little or no phagocytosis by $C$. virginica haemocytes. Some differences were found in the percentage of phagocytic hyalinocytes depending on the phago- cytosis stimulant used. However, the percentage of phagocytic granulocytes was similar in all the assays. La Peyre et al. (1995) found a significant difference in the percentage of phagocytic haemocytes between assays using $P$. marinus trophozoites and those using zymosan

According to Cheng (1983) and Renwrantz (1990), the phagocytic process can be subdivided into 4 steps: (1) chemotaxis, involving the attraction of the phagocyte to the non-self material, (2) recognition, involving the attachment of the foreign material to the surface of the phagocyte, (3) internalization, and (4) intracellular degradation. Light and electron microscopy studies of the phagocytic process by clam haemocytes demonstrated internalization and degradation but chemotaxis and recognition phases were not considered.

Internalization of foreign particles by clam haemocytes occurred by invagination of the cell surface followed by pseudopod formation and particle internalization into endocytotic vacuoles (primary phagosome). A similar model was described by Cheng (1975). Two more models of the same event were described by Bang (1961) and Renwrantz et al. (1979).

Our fine structural observations indicate that intracellular degradation of internalized material occurs in secondary phagosomes of the clam haemocytes. In the phagocytosis assays, fusion between granules and the primary phagosome was not observed, but haemocytes with secondary phagosomes contained fewer granules. It is possible that secondary phagosomes result from the fusion of lysosomes with primary phagosomes. Auffret (1986) suggested that the formation of secondary phagosomes results from the fusion of granules and primary phagosomes in Ostrea edulis. Nevertheless the loss of granules from granulocytes of Ruditapes decussatus during the in vitro phagocytosis assays could also be due to the release of lysosomal enzymes from granulocytes into the serum (degranulation). A degranulation process associated with phagocytosis was reported by Foley et al. (1977) in Mercenaria mercenaria and Hinsch \& Hunte (1990) in Crassostrea virginica.

In this phase, lysosomal enzymes play a very important role. Mohandas et al. (1985) and Oubella et al. (1994) demonstrated that challenge with bacteria produced a hypersynthesis of lysosomal enzymes by haemocytes. A number of lysosomal enzymes were de- 
tected in Ruditapes decussatus haemocytes and the presence of acid phosphatase in the granules suggests that these granules are lysosomes (López et al. in press). The presence of lysosomal enzymes in bivalve mollusc haemocytes was cited by several authors (Moore \& Gelder 1985, Feng 1988, Beckmann et al. 1992). The absence of oxidative metabolism coupled to phagocytosis in $R$. decussatus haemocytes was previously reported (López et al. 1994).

Cheng (1981) described 2 models of intracellular degradation of phagocytosed materials in bivalve haemocytes. One of them involved diffusion of molecules through the phagosomal membrane into the cytoplasm after enzyme digestion. Glucose is then polymerized into glycogen in the cytoplasm. Indigestible material remains as residual bodies which are eventually discharged from the cell. The other model suggests digestion of bacteria beginning within a primary phagosome. The material is transferred from primary to secondary phagosomes and glycogen granules are synthesized from glucose inside these phagosomes. Then, the secondary phagosomal wall disintegrates and the glycogen granules are freed into the cytoplasm.

In our study, transference of digested material from primary to secondary phagosomes was not detected. However, glycogen granules were detected inside secondary phagosomes. Discharged residual bodies were also observed in Ruditapes decussatus haemocytes.

Acknowledgements. We thank the team of Eric Mialhe (IFREMER, La Tremblade, France) for supplying the Vibrio P1 bacteria. The clams for this study were supplied by Manuel Franco. This study was partially supported by a scholarship of Caixa de Galicia in 1991. for C.L. during a stay at the IFREMER laboratory.

\section{LITERATURE CITED}

Anderson RS (1994) Hemocyte-derived reactive oxygen intermediate production in four bivalve mollusks. Dev Comp Immunol 18(2):89-96

Auffret $M$ (1986) Internal defence in bivalve molluscs: ultrastructural observations on the fate of experimentally injected bacterial in Ostrea edulis granular hemocytes. In: Vivarès CP, Bonami JR, Jaspers E (eds) Pathology in marine aquaculture. European Aquaculture Society, Bredene, Special Publ 9, p 351-356

Auffret M (1988) Bivalve hemocyte morphology. In: Fisher WS (ed) Disease processes in marine bivalve molluscs. American Fisheries Society Special Publication 18, Bethesda, MD, p 169-177

Azevedo C (1989) Fine structure of Perkinsus atlanticus n. sp. (Apicomplexa, Perkinsea) parasite of the clam Ruditapes decussatus from Portugal. J Parasitol 75(4):627-635

Bang FB (1961) Reaction to injury in the oyster (Crassostrea virginica). Biol Bull (Woods Hole) 121(1):57-68

Beckman N, Morse MP, Moore CMI (1992) Comparative study of phagocytosis in normal and diseased hemocytes of the bivalve Mya arenaria. J Invertebr Pathol 59:124-132

Cheng TC (1975) Functional morphology and biochemistry of molluscan phagocytes. Am NJ Acad Sci 266:343-379

Cheng TC (1981) Bivalves. In: Ratcliffe NA, Rowley AF (eds) Invertebrate blood cells. Academic Press, London, p 233-300

Cheng TC (1983) Internal defense mechanisms of molluscs against invading microorganisms: personal reminiscences. Trans Am Microsc Soc 102(3):185-193

Clare AS, Lumb G (1994) Identification of haemocytes and their role in clotting in the blue crab. Callinectes sapidus. Mar Biol 118:601-610

Dikkeboom R, Tijnagel JMGH, Mulder E, Knaap van der WPW (1987) Hemocytes of the pond snail Lymnaea stagnalis generate reactive forms of oxygen. J Invertebr Pathol 49:321-331

Feng SY (1966) Experimental bacterial infection in the oyster Crassostrea virginica. J Invertebr Pathol 8:505-511

Feng SY (1967) Responses of molluscs to foreign bodies, with special reference to the oyster. Fed Proc 26(6):1685-1692

Feng SY (1988) Cellular defence mechanisms of oysters and mussels. In: Fisher WS (ed) Disease processes in marine bivalve molluscs. American Fisheries Society Special Publication 18, Bethesda, MD, p 153-168

Feng SY, Stauber LA (1968) Experimental hexamitiasis in the oyster Crassostrea virginica. J Invertebr Pathol 10:94-110

Foley DA, Cheng TC (1975) A quantitative study of phagocytosis by hemolymph cells of the pelecypods Crassostrea virginica and Mercenaria mercenaria. J Invertebr Pathol 25:189-197

Foley DA, Cheng TC (1977) Degranulation and other changes of molluscan granulocytes associated with phagocytosis. J Invertebr Pathol 29:321-325

Fries CR, Tripp MR (1980) Depression of phagocytosis in Mercenaria mercenaria following chemical stress. Dev Comp Immunol 4:233-244

Hawkins EW, Howse RD (1982) Ultrastructure of cardiac hemocytes and related cells in the oyster Crassostrea virginica. Trans Am Microsc Soc 101(3):241-252

Hinsch GW, Hunte M (1990) Ultrastructure of phagocytosis by hemocytes of the American oyster. In: Perkins FO, Cheng TC (eds) Pathology in marine science. Academic Press, San Diego, p 479-488

Hose JE, Martin GG, Gerard AS (1990) A decapod hemocyte classification scheme integrating morphology, cytochemistry, and function. Biol Bull (Woods Hole) 178:33-45

La Peyre JF, Chu FLE, Meyers JM (1995) Haemocytic and humoral activities of eastern and Pacific oysters following challenge by the protozoan Perkinsus marinus. Fish \& Shellfish Immunol 5:179-190

Lauckner G (1983) Diseases of Mollusca: Bivalvia. In: Kinne O (ed) Diseases of marine animals, Vol II. Biologische Anstalt Helgoland, Hamburg, p 477-961

Le Gall G. Mialhe E (1992) Purification of rickettsiales-like organisms associated with Pecten maximus (Mollusca: Bivalvia): serological and biochemical characterization. Dis Aquat Org 12:215-220

López C, Carballal MJ, Azevedo C, Villalba A (1997) Morphological characterization of the hemocytes of the clam, Ruditapes decussatus (Mollusca: Bivalvia). J Invertebr Pathol 69:51-57

López C, Carballal MJ, Azevedo C, Villalba A (in press) Enzyme characterization of the circulating haemocytes of the carpet shell clam, Ruditapes decussatus (Mollusca: Bivalvia), in relation to defence function. Fish \& Shellfish Immunol 
López C, Villalba A, Bachère E (1994) Absence of generation of active oxygen radicals by the hemocytes of the clam, Ruditapes decussatus (Mollusca: Bivalvia) coupled with phagocytosis. J Invertebr Pathol 64:188-192

Mialhe E, Bachére E, Chagot D, Grizel H (1988) Isolation and purification of the protozoan Bonamia ostreae (Pichot et al. 1980), a parasite affecting the flat oyster Ostrea edulis L. Aquaculture 71:293-299

Mialhe E, Bachère $E$, Le Bec C, Grizel H (1985) Isolement et purification de Marteilia (Protozoa: Ascetospora), parasites de bivalves marins. C R Acad Sci Paris Ser III 301. $137-142$

Mohandas A, Cheng TC, Cheng JB (1985) Mechanism of lysosomal enzyme release from Mercenaria mercenaria granulocytes: a scanning electron microscope study. J Invertebr Pathol 45:189-197

Moore CA, Gelder SR (1985) Demonstration of lysosomal enzymes in hemocytes of Mercenaria mercenaria (Mollusca: Bivalvia). Trans Am Microsc Soc 104(3): 242-249

Oubella R, Paillard C, Maës P, Auffret M (1994) Changes in hemolymph parameters in the Manila clam Ruditapes philippinarum (Mollusca: Bivalvia) following bacterial challenge. J Invertebr Pathol 64:33-38

Editorial responsibility: Albert Sparks, Seattle, Washington, USA
Paillard C, Maës P, Oubella R (1994) Brown ring disease in clams. Annu Rev Fish Dis 4:219-240

Pipe RK, Holden JA, Farley SR (1994) The separation and characterisation of haemocytes from the marine mussel Mytulus edulis. Dev Comp Immunol (S1):113

Ray SM (1966) A review of a culture method for detecting Dermocystidium marinum with suggested modifications and precautions. Proc Natl Shellfish Assoc 54:55-80

Renwrantz L (1990) Internal defense system of Mytilus edulis In: Stefano GB (ed) Neurobiology of Mytilus edulis Studies in Neuroscience, No. 2, Manchester University Press, Manchester, p 257-275

Renwrantz L, Yoshino T, Cheng T, Auld K (1979) Size determination of hemocytes from the American oyster Crassostrea virginica, and the description of a phagocytosis mechanism. Zool Jb Physiol 83:1-12

Ruddell CL (1971) Elucidation of the nature and function of the granular oyster amebocytes through histochemical studies of normal and traumatized oyster tissues. Histochemie 26:98-112

Suzuki T, Yoshinaka R, Mizuta S, Funakoshi S, Wada K (1991) Extracellular matrix formation by amebocytes during epithelial regeneration in the pearl oyster Pinctada fucata. Cell Tissue Res 266:75-82

Manuscript received: September 9,1996 Revised version accepted: May 20, 1997 